\title{
Effect of Gender on Students' Test Scores in Progresa
}

\author{
Wang Yalin ${ }^{1,+}$, Meng Wenxuan ${ }^{2,+}$, Luo Wentao ${ }^{3,+}$, Wu Yude W,+ $^{4,}$ \\ ${ }^{1}$ Finance, Southern China Agriculture University, Guangzhou, China,1208886162@qq.com \\ ${ }^{2}$ Beijing Saint Paul American School, Beijing, China, 13126688883@qq.com \\ ${ }^{3}$ Business economics, University of California, San Diego, California, United States, drm88lwt@163.com \\ ${ }^{4}$ RDFZ Chaoyang Branch School,Beijing, China,Yh173988@163.com \\ + They are all the first authors.
}

\begin{abstract}
Study habits are variable between male and female. Significant differences of academic performance among elementary and middle school male and female Mexican students has been a challenge concern to Mexican education system. This research, therefore, sought to examine the gender differences in access for study habits. To achieve the goal, the paper will adapt with econometric model and analysis the consequences brought by different study habits. Data provided by Professor Todd were used for the study. The result presented significant differences in the study habits of students on the basis of gender.
\end{abstract}

Keywords: test scores, gender difference, school performance, Progresa.

\section{INTRODUCTION}

There has been a public outcry over the low academic achievement of Mexican elementary and middle school students. Thus, Data Dictionary was made to investigate factors that influence students' academic achievement.

In terms of educational attainment women lag behind men in Mexico. The 1972 National Longitudinal Survey and the 1988 National education Longitudinal Survey illustrates the difference between male and female students' education performance. It's indicate that boys' math scores were 0.25 standard deviations higher than girls' math score. The result recounts a fact that gender is the factor in determining student performance. Also, from the psychological status. Information available on gender differences in high school students demonstrates a consistent dominance in psychological resources and school performance in Mexican female students (Blanco, Ornelas, Aguirre, \& Guedea, 2012[1]; Contreras \& Lozano, 2011[2]; De Garay \& Del Valle, 2012[3]; Flores \& Gómez, 2010[4]). Hence, these study grow out of curiosity to find how gender hold for students' education performance in school.

Table 1 Meanings of variables

\begin{tabular}{|l|l|l|}
\hline Variable & Question & Values \\
\hline Class_Attenti on & How often do you pay attention in & A - never \\
& your classes? & B - almost never \\
& & C - sometimes \\
& & D - almost always \\
& & E - always \\
\hline
\end{tabular}




\begin{tabular}{|c|c|c|}
\hline $\begin{array}{l}\text { Clas } \\
\text { S } \\
\text { Parti cipat ion }\end{array}$ & $\begin{array}{l}\text { How often do } \\
\text { you participate in class? }\end{array}$ & $\begin{array}{ll}\text { A } & \text { - never } \\
\text { B } & \text { - almost never } \\
\text { C } & \text { - sometimes } \\
\text { D } & \text { - almost always } \\
\text { E } & \text { - always }\end{array}$ \\
\hline $\begin{array}{l}\text { Acti } \\
\text { vitie } \\
\text { s } \\
\text { Parti cipat ion }\end{array}$ & $\begin{array}{l}\text { How often do } \\
\text { you participate in sports or cultural } \\
\text { a c t i viti e s i n } \\
\text { school? }\end{array}$ & $\begin{array}{ll}\text { A } & \text { - never } \\
\text { B } & \text { - almost never } \\
\text { C } & \text { - sometimes } \\
\text { D } & \text { - almost always } \\
\text { E } & \text { - always } \\
\end{array}$ \\
\hline Skip_S chool & $\begin{array}{l}\text { How often do you } \\
\text { miss school? }\end{array}$ & $\begin{array}{ll}\text { A } & \text { - never } \\
\text { B } & \text { - almost never } \\
\text { C } & \text { - sometimes } \\
\text { D } & \text { - almost always } \\
\text { E } & \text { - always }\end{array}$ \\
\hline $\begin{array}{l}\text { Att end } \\
\overline{\text { Sch ool }}\end{array}$ & $\begin{array}{l}\text { How often do you NOT go to classes while } \\
\text { b e ing a t } \\
\text { school? }\end{array}$ & $\begin{array}{ll}\text { A } & \text { - never } \\
\text { B } & \text { - almost never } \\
\text { C } & \text { - sometimes } \\
\text { D } & \text { - almost always } \\
\text { E } & \text { - always } \\
\end{array}$ \\
\hline Read_F un & $\begin{array}{l}\text { In your free } \\
\text { time, how often do you read for fun? }\end{array}$ & $\begin{array}{l}\text { A } \quad \text { - never } \\
\text { B - once a week } \\
\text { C } \quad \text { - twice a week } \\
\text { D - thrice a week } \\
\text { E - four times a week } \\
\text { F - every day } \\
\text { Not Present }\end{array}$ \\
\hline
\end{tabular}

This questionnaire show the variables that were considered in the research. The above background and variables have given rise to research efforts to find the relationship between gender differences and study habits for tackling poor academic performances of Mexican students. Since the database for whole Mexican students education performance is larger, the present study has narrowed down on age and years of schooling. The paper focus on the Mexico students between grade 4 to grade 8 and we analyze the data that provided in 2008.

\section{METHODOLOGY}

OLS model is one of the most popular and promising method to analyze the data. It is a method that allows investigator to get the correlation between dependent variables and independent variables.

\section{LITERATURE REVIEW}

Normally, people consider boys to be good at science whereas girls are skilled at liberal art, and this point is proved by the previous research and studies. Analyzing data on test scores of twelfth graders from the 1972
National Longitudinal Survey and the 1988 National education Longitudinal Survey, in 1972 boys had average math scores that were 0.25 standard deviations higher than those of girls, while girls had a slight edge of 0.035 standard deviations in average reading scores. By 1992, the girls had cut into the average math gap by 0.17 standard deviations and had added to their lead in reading (Devin G. Pope and Justin R. Sydnor, 2010)[5]. In a meta-analysis of 100 studies of math tests, Hyde, Fennema, and Lamon concluded that the average standardized difference in test scores between males and females was actually very small and statistically insignificant. However, the variance of test scores differs substantially by gender, that clearly more males have very high test scores than females on science and math tests and clearly more females score very high ranges on language and reading tests. While looking at the variables that affect the Math and Spanish scores of secondary students in Mexico, it is not objective to just discuss one possible influential factor, so that is where student engagement in school should be taken into account. When students have stronger engagement with school, their achievements are positive (Christopher C. Weiss and Emma García, 2015)[6], no matter what 
gender they are. A study using national data found that students who actively participate and pay attention in class have significantly higher test scores in high school (Ainsworth-Darnell and Douglas Downey, 1998)[7]. Using data from various samples, a number of empirical studies have pointed out a generally consistent relationship between students' engagement in school and academic achievement (Connell et al. 1994[8]; Fredricks et al. 2004[9]; Marks 2000[10]). Besides, students' engagement in school is also about the sense of belonging, from the psychological side. Information available on gender differences in high school students demonstrates a consistent dominance in psychological resources and school performance in Mexican female students (Blanco, Ornelas, Aguirre, \& Guedea, 2012[1]; Contreras \& Lozano, 2011[2]; De Garay \& Del Valle, 2012[3]; Flores \& Gómez, 2010[4]). Nevertheless, there are several differences lie in the previous studies and this research, for the age level, country diversity, and the variable choice. The survey in 1972 and 1988 investigate twelfth graders, while the main focus of this research is on secondary students, who are aged about 13-16. And some of the studies took place in Canada and the United States, which do not show exactly the situation in Mexico. This research paper also examines the relationship between family income and students' Math and Spanish scores, and whether the study hour and activity participation could be influential variables.

\section{DESCRIPTIVE DATA}

Table 2 Characteristics of variables

\begin{tabular}{|c|c|c|c|c|}
\hline Variable & mean & var & $\max$ & $\min$ \\
\hline CAL_ESP08 & 526.65 & 11345.72 & 876.99 & 280.78 \\
\hline CAL_MAT08 & 515.8 & 12798.45 & 866.42 & 226.11 \\
\hline AP08 & 2.75 & 1.69 & 4 & 0 \\
\hline ACS08 & 0.82 & 1.37 & 4 & 0 \\
\hline CA08 & 3.31 & 0.77 & 4 & 0 \\
\hline CP08 & 2.71 & 1.07 & 4 & 0 \\
\hline HS08 & 1.75 & 1.19 & 4 & 0 \\
\hline FI08 & 2.35 & 1.62 & 6 & 1 \\
\hline
\end{tabular}

\subsection{Test Score}

The table 2 shows the mean and variance of maths test score (CAL_MAT08) are 515.8 and 12798.45 respectively. And the range of this variable is 640.31 , with the maximum 866.42 and the minimum 226.11 . From the mean, we know that different scores have uniform distribution though the big variance shows the fact that the gap of different students' test scores are huge. In contrast to Spanish test score, the distribution of maths test score is more disperse. Like maths test score, Spanish test score (CAL_ESP08) is also a dependent variable that reflect the study performance under different gender. As the table shows, this indicator has a mean of 526.65 and a variance of 11345.72, and its maximum and minimum are 876.99 and 280.78, respectively. From the mathematic average, we know that the number of students who have the Spanish test score higher than 526.65 is similar to that of students who have the Spanish test score lower than 526.65, otherwise, the mean would be close to max or min.

\subsection{School Performance}

The school performance is evaluated through the following 5 variables: Activities_Participation08, Attend_Class_In_School08, Class_Attention08, Class_Participation08 and Hours_Study08. Activities_Participation08 and Attend_Class_In_School08 measure the students' participation in school activities. Class_Attention08 and Class_Participation08 evaluate the students' participation in class. And Hours_Study08 shows the time the students spend on studying in their spare time. In order to quantify the above indexes, corresponding numeric variables for each variable have to be generated. For example, the corresponding variable activities_participation07 generated for the variable activities_participation07 is AP07, and Level A corresponds to number 0 , level B corresponds to number 1 , and so on. The data characteristics of these variables are shown as the following contents. The variable AP measures the frequency students take part in sports or cultural activities in school. The average value of AP is around 2.5. Among them, AP10 has the largest mean, equal to 2.868, while AP13 has the smallest mean, equal to 2.413. The fluctuation range of all variables is roughly the same, among which AP10 has the smallest fluctuation range, so it is reasonable to believe that AP10 students are participating in the most school activities.

AC means how many students don't go to school. The mean of these variables is only about 1 , which means most students are concerned about their class.

After the same treatment, the numerical characteristics of CA represent how often the students pay attention to their class and the larger the figure is, the more often the students concentrate on the class. The mean values are all above 3 , which indicates that students pay high attention to the class and the standard deviation of each variable is around 1 , which proves that the degree of fluctuation is relatively small.

Compared with the above variables, $\mathrm{CP}$ reflects the frequency of class attendance. The mean of $\mathrm{CP}$ is around 2.6, which is a little lower than we expected. Besides, the standard deviation is large, indicating that the difference between students is strong.

The final variable describing the school performance of students is HS, which quantifies the time students 
spend on their studies in their spare time. According to the analysis, the difference between the grades is not very obvious. Almost the average time of every grade on study is 1.6 hours, which maybe is not very high compared with the students in China.

According to a previous paper (A Case Study of Mexico and Factors Affecting Burnout and School Engagement), school participation has a significant effect on improving learning attitude and academic performance. Thus, to improve the grades of students, it's necessary to motivate students to participate in school and classroom activities and besides, the increase of time students spend on studying is also needed.

\subsection{Family Background}

Family income is a special variable that included in the research. Considering the influences brought by Family income, a questionnaire is made to investigate family background, especially searching for Mexican monthly family income on the quality and nature of parent's involvement in their children's education. The results revealed that there was a certain degrees of effect of family income level on the components of academic performance. There are five levels of family income and data indicates that Family income(FI08) has a mean value of 2.35, thereby saying the mean family income is Mexico is about 1750 pesos; and has a variance of 1.62 respectively. The maximum value of family income (FI08) is 6 while the minimum value is 1 .

\section{THEORETICAL ANALYSIS}

In general, it is common that girls have a better academic self-concept and a higher achievement motivation than boys (Angel Alberto Valdés-Cuervo et al, 2015[11]) So female students may be more selfdisciplined in study than male students. We can establish the first hypothesis.

Hypothesis 1: Female students will outperform male students in test scores and school performance.

When a family is wealthier, it will pay more attention to children's education. The students in those families can not only attend class that they are interested in, but also have more access to solve the problem in study such as after-school tutoring. Thus, we can draw an another hypothesis.

Hypothesis 2: Higher family income will contribute to better study.

\section{EMPIRICAL ANALYSIS}

\subsection{Model 1}

We firstly progressed the data in a elementary statistic way, which counted the numbers of male students and female students under different level of NE08, NM08, AP08, ACS08, CA08, CP08 and HS08, which are level of Spanish test scores, Maths test scores, activities participation, attend classes in school, class attention, class participation and hours in study. As the level of dependent variables goes higher, it means that students' performance in this field is better, besides, Sexo " 0 " denotes male student and " 1 " denotes female students. The result is as figure 1 shows. 


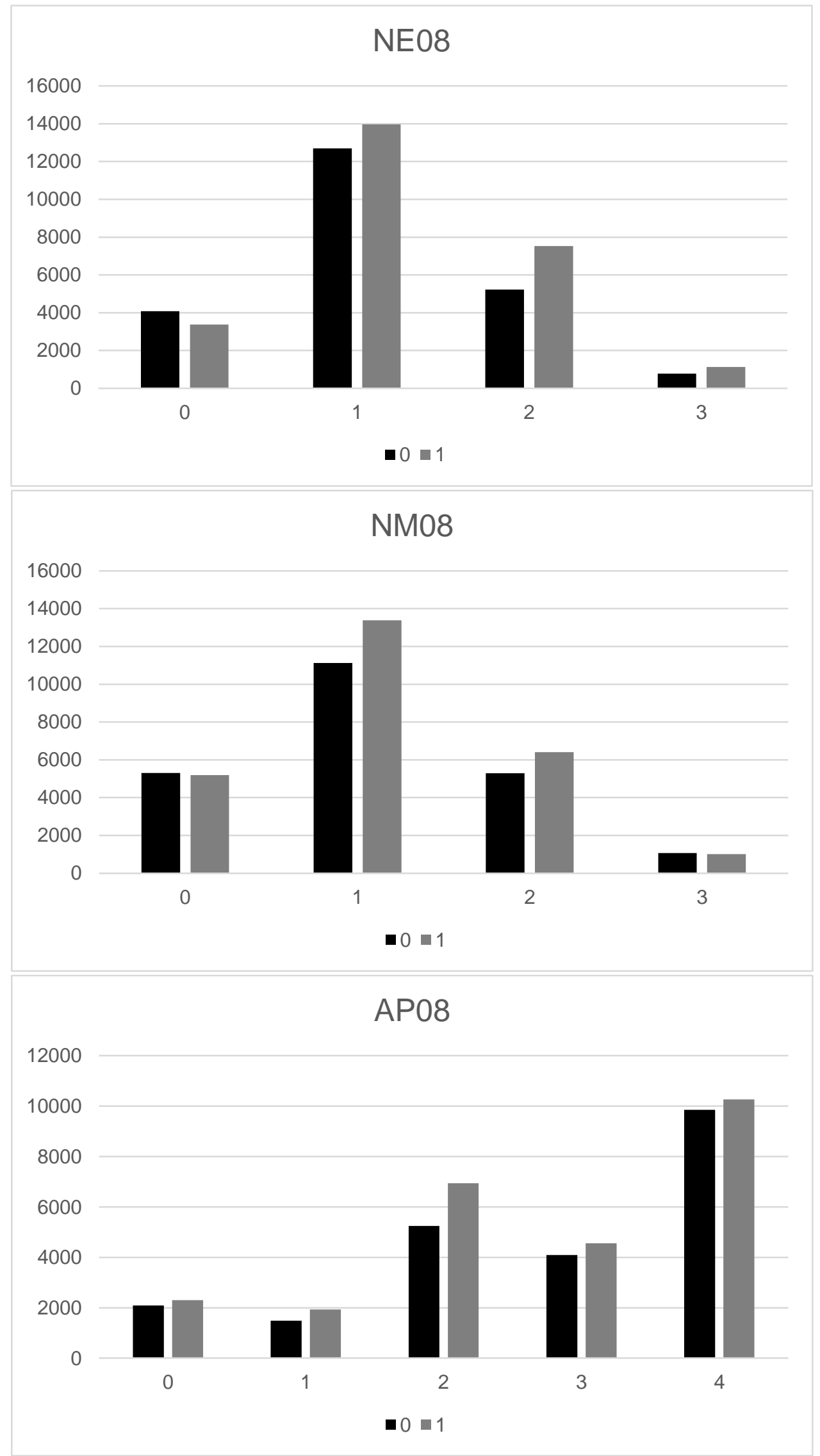




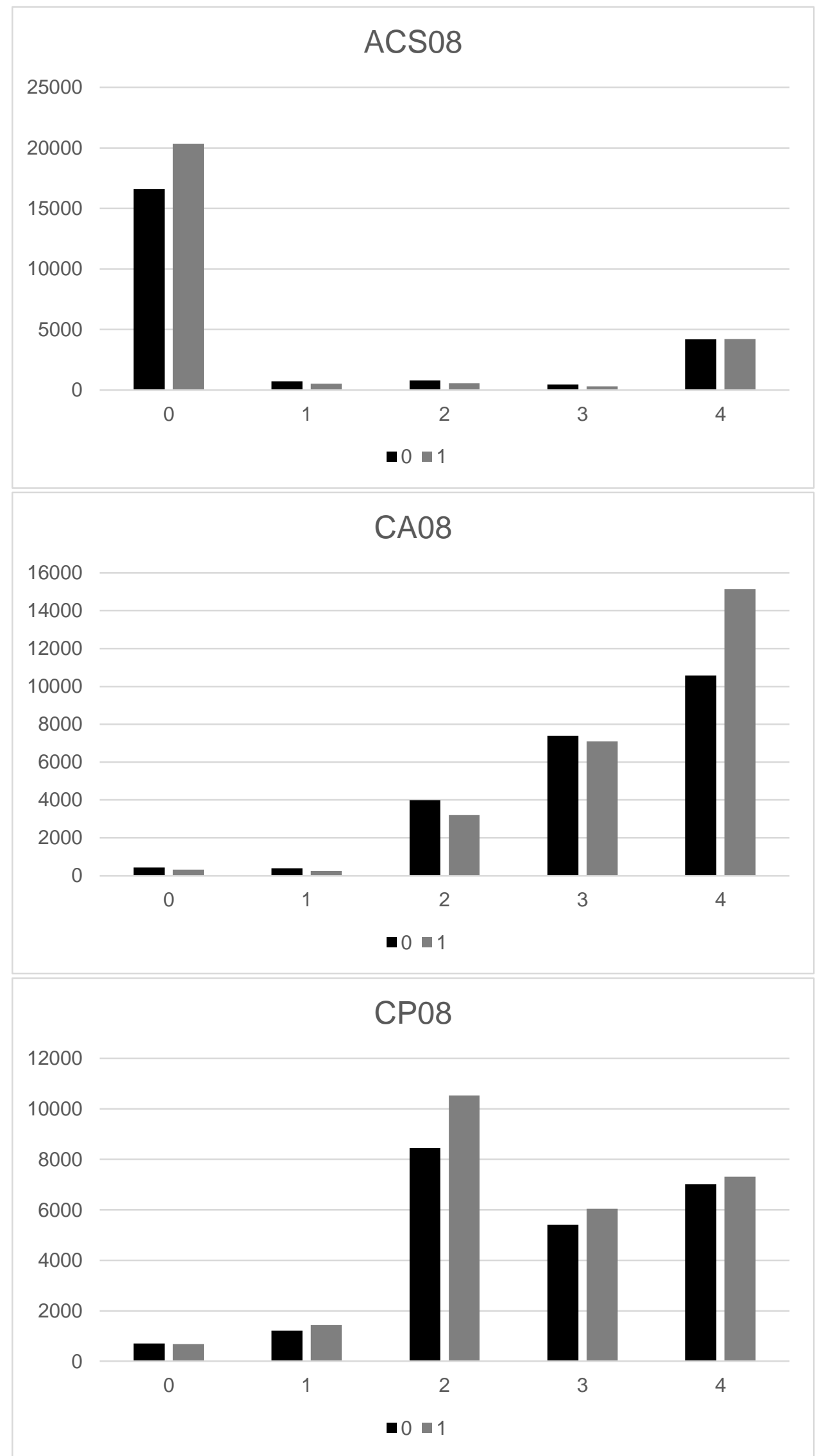




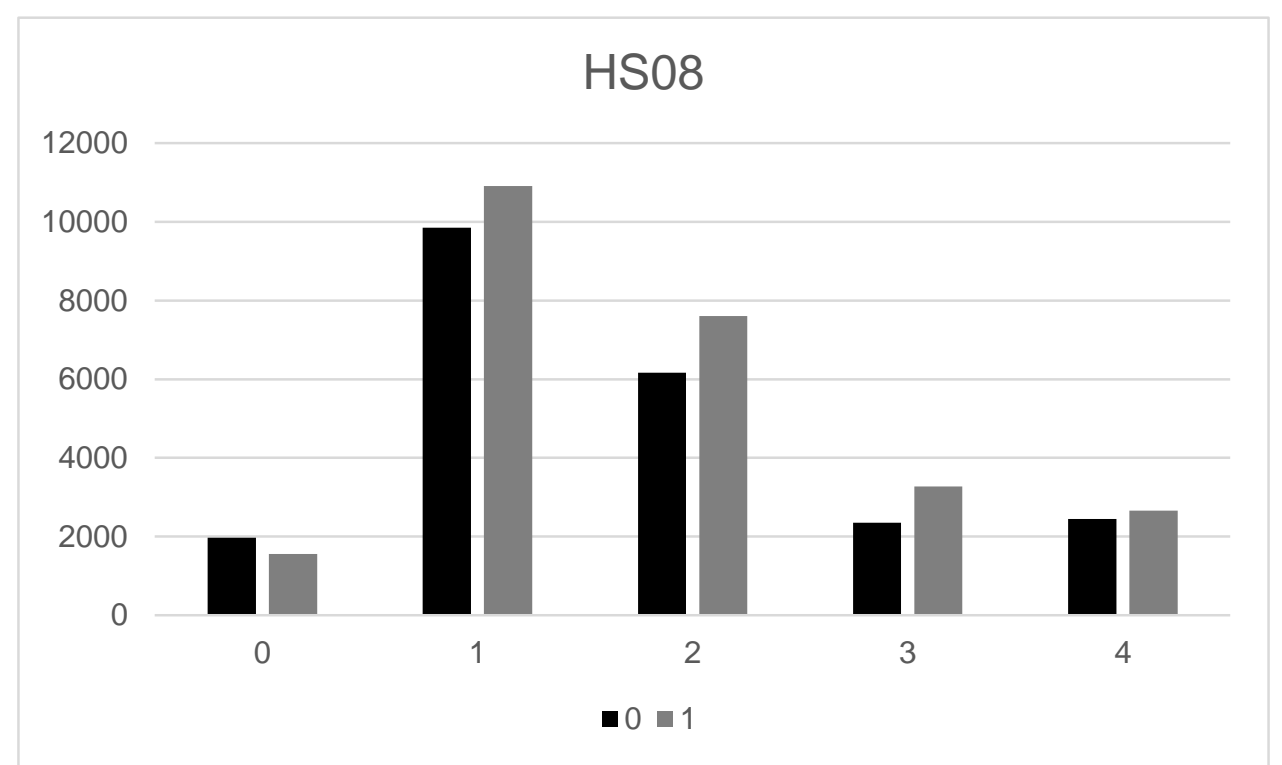

Figure 1 The numbers of male students and female students under different level of variables

From the figure 1, we can firstly learn the gap of numbers in different gender under each variable. It is clear that the gaps of NE08 and CA08 are more noticeable, whereas the gap of CP08 is not so evident. In summary, the conclusion that gender can affect some kinds of students' school performance and test scores can be drawn from the graphs above.

However, there are some problem with this method that will make the process of drawing the conclusion not cautiously enough. It is likely that the numbers of female students is significantly more than that of male students, this possibility will lead to evident gap between different gender under those variables. Thus, next method is the ordinary least square model, which examines gender's effect on different variables.

\subsection{Model 2}

Table 3 Gender's effect on different dependent variables

\begin{tabular}{|c|c|c|c|}
\hline & $\beta$ & t value & ${\text { adjusted } \mathrm{R}^{2}}$ \\
\hline CAL_ESP08 & $21.1258^{* * *}$ & 22.03 & 0.0098 \\
\hline CAL_MAT08 & $5.7944^{* * *}$ & 5.646 & 0.0006 \\
\hline AP08 & $-0.0818^{* * *}$ & -6.934 & 0.0009 \\
\hline ACS08 & $-0.1499^{* * *}$ & -10.74 & 0.0023 \\
\hline CA08 & $0.2069^{\star * *}$ & 26.15 & 0.0138 \\
\hline CP08 & $-0.0507^{* * *}$ & -5.402 & 0.0006 \\
\hline HS08 & $0.0779^{* * *}$ & 7.879 & 0.0013 \\
\hline
\end{tabular}

Table 3 presented gender's effect on CAL_ESP08, CAL_MAT08, AP08, ACS08, CA08, CP08 and HS08. This time we changed NE08 and NM08 into CAL_ESP08 and CAL_MAT 08 because the former two are the levels of Spanish test scores and Maths test scores and the latter two are the real test scores, which are more suitable to show the relationship with gender. The first row denotes the characteristics of gender, including the coefficient, $\mathrm{t}$ value and adjusted $\mathrm{R}^{\wedge} 2$, we can learn whether gender plays a significant role in each dependent variable and how much it works. The first column denotes dependent variable in each model. It is evident that gender has a positive and significant relationship with Spanish test scores, Maths test scores, class attention and hours in study, this means girls perform better than boys in these fields. However, boys may outperform girls in activities participation, attend class in school and class participation, for gender has a negative and significant relationship with them. So girls may have higher test score and spend more time studying than boys, but boys may take more active part in school activities and classes than girls.

However, the adjusted $\mathrm{R}^{\wedge} 2$ of each model is too small, which means independent variable cannot totally explain the change of dependent variable. Additionally, the coefficient of gender under different variables is also small. 


\subsection{Model 3}

Table 4 The effect of gender and family income on dependent variables

\begin{tabular}{|c|c|c|c|c|c|c|c|}
\hline & CAL_ESP08 & CAL_MAT08 & AP08 & ACS08 & CA08 & CP08 & HS08 \\
\hline Sexo & $21.2102^{* * *}$ & $5.8177^{* * *}$ & $-0.818^{* * *}$ & $-0.1502^{* * *}$ & $0.2069^{* * *}$ & $\begin{array}{c}-0.0507 \\
* * *\end{array}$ & $0.0779^{* * *}$ \\
\hline FI08 & $26.2996^{* * *}$ & $25.1971^{* * *}$ & $0.0304^{* * *}$ & $-0.1856^{* * *}$ & $0.0225^{* * *}$ & $0.0195^{* * *}$ & 0.0011 \\
\hline adjusted R & 0.1085 & 0.0809 & 0.0018 & 0.0259 & 0.0149 & 0.0011 & 0.0012 \\
\hline
\end{tabular}

In this method, we added a new independent variable "family income"(FI08) to the model to see whether it can increase the goodness of fit of these models and strengthen the effect of gender. The result is as table 4 shows, the first row denotes the dependent variable of each model and the first column denotes the independent variables of that model, each data is about the coefficient of the independent variable in the same row. From the table 4, the magnitude of gender's effect clearly gets bigger, and the adjusted R squares also increase. Except for ACS08 and HS08, we can know from this change that family background plays an important role in students' study, since family income is significant and positive in most of the models. Besides, the independent variable also have a strong effect on Spanish test scores and Maths test scores. It is likely that higher family income contributes to better performance in school, and the reason may be that students have better condition to study or they have more access to gain knowledge such as extracurricular learning.

\section{CONCLUSION}

After setting three models to analyze gender's effect on test scores, we finally chose model 3 to make final conclusion because family income does have important impact on students' study and adding it to the regression model will increase the validity of the results.

From the regression result in model 3, it is found that gender can predict both Spanish test scores and Maths test scores. Besides, this independent variable also have significant positive relationship with CA08 and HS08, but have significant negative relationship with AP08, ACS08 and HS08. So the hypothesis 1 that girls may do better in test scores and school performance is not totally correct. In terms of family income, most of dependent variables can be positively influenced by it. This result may be interpreted that when family income is higher, students will be more accessible to after-school classes and get tutoring, finally they are more likely to perform well in tests. When the sense of achievement is positive, students will be more liable to participate in school activities more, they are more internally motivated toward lessons, and their academic achievement is
higher(M. Yüksel Erdoğdu, 2019[12]). Therefore, the hypothesis 2 conforms to the empirical result.

\subsection{Limitation}

Although we use more than 50,000 samples to set the model, there are still some limitations that will affect the accuracy of the result.

Region limitation. The students we choose are from Mexico, so the result may be valid in this country. However, because of different education systems in different countries, it is likely that disciplines are assessed by different criteria.

Consequently, test score cannot well reflect the effect of gender differences. Hence to make the regression result more acceptable, it is better to collect data from more than two regions.

Variables limitation. In this study, we use Spanish test score, maths test score, activities participation, attend class in school, class attention, class participation and hours study to show students' school performance and study habits. The gender and family income are independent variables in the study. Nevertheless, there are many other indicators reflecting students' study and there are lots of factor influencing students' study, so the variables we have used may not comprehensive enough and it will be better if we add more indicators such as the quality of students' homework,

\subsection{Advice}

In this study, it is found that gender does have a prominent effect on students' study, which means that there are still some differences between female students and male students. So the school may need to focus more on efficiently teaching, which means pay more attention to those who are poor in study. There are some phenomena that present low level of school engagement, the students tend to come to school late, have no desire to learn and they exhibit problematic behaviors at school (M. Yüksel Erdoğdu, 2019[12]), and all of these may lead to low grade in test. Additionally, some students may be desire to knowledge but such learning resources are unavailable to them due to low family income. Thus, it is 
generous of schools to subsidy students in low family income.

\section{REFERENCES}

[1] Blanco, H., Ornelas, M., Aguirre, J., \& Guedea, J. (2012). Autoeficacia percibida en conductas. académicas [Perceived self-efficacy in academic behaviors]. Revista Mexicana de Investigación Educativa, 17, 557-571.

[2] Contreras, Y., \& Lozano, A. (2011, October). Aprendizaje auto- regulado como competencia para el aprovechamiento de los estilos de aprendizaje en alumnos de educación superior [Self- regulated as competition for the use of learning styles in higher education students learning]. Paper presented at XI Mexican Congress of Educational Research, Federal District, Mexico.

[3] De Garay, A., \& Del Valle, G. (2012). Una mirada a la prescencia de las mujeres en la educacion. superior en México [A look at the presence of women in university education in Mexico]. Revista Iberoamericana de Educación Superior, 3(6), 3-30.

[4] Flores, R., \& Gómez, J. (2010). Un estudio sobre la motivación hacia la escuela secundaria en. estudiantes mex- icanos [A study of motivation in Mexican secondary stu- dents]. Revista Electrónica de Investigación Educativa, 12 (1).

[5] Devin G. Pope is Assistant Professor of Operations and Information Management, Wharton School, University of Pennsylvania, Philadelphia, Pennsylvania. Justin R. Sydnor is Assis- tant Professor of Economics, Weatherhead School of Management, Case Western Reserve University, Cleveland, Ohio.

[6] Student Engagement and Academic Performance in Mexico: Evidence and Puzzles from PISA Author(s): Christopher C. Weiss and Emma García Comparative Education Review, Vol. 59, No. 2 (May 2015), pp. 305-331

[7] Ainsworth-Darnell, James, and Douglas Downey. 1998. "Assessing the Opposi- tional Culture. Explanation for Racial/Ethnic Differences in School Performance." American Sociological Review 63:536-53.

[8] Connell, James Patrick, Margaret Beale Spencer, and J. Lawrence Aber. 1994. "Edu- cational Risk and Resilience in African-American Youth:Context, Self, Action, and Outcomes in School." Child Development 65 (2): 493-506.

[9] Fredricks, Jennifer A., P. C. Blumenfeld, and A. H. Paris. 2004. "School Engage- ment: Potential of. the
Concept, State of the Evidence." Review of Educational Research 74 (1): 59-109.

[10] Marks, Helen M. 2000. "Student Engagement in Instructional Activity: Patterns in the Elementary, Middle, and High School Years." American Educational Research Journal 37 (1): 153-84.

[11] Angel Alberto Valdés-Cuervo, Pedro Antonio Sánchez Escobedo \& María Dolores. ValadezSierra (2015) Gender differences in self-concept, locus of control, and goal orientation in Mexican high-achieving students, Gifted and Talented International, 30:1-2, 19-24

[12] M. Yüksel Erdoğdu (2019) The Mediating Role of School Engagement in the Relationship between Attitude toward Learning and Academic Achievement, [J]Volume 7, Issue 2. 2019. PP 75-81 